\title{
Strategi Komunikasi Politik Pemenangan Kepala Daerah
}

\author{
Yohanes De Britto Bimo Triwicaksono" ${ }^{1}$, Adi Nugroho' \\ ${ }^{1}$ Magister Ilmu Komunikasi, Fakultas Ilmu Sosial dan Politik, Universitas Diponegoro \\ Jl. Erlangga Barat 7 No. 33, Pleburan. Kecamatan Semarang Selatan, Kota Semarang, Jawa Tengah \\ Email: ${ }^{1}$ bimodebritto@gmail.com
}

Received: April 2021; Accepted: Mei 2021; Published: Juni 2021

\begin{abstract}
This research is motivated by the importance of political communication strategies for winning in regional head elections. The purpose of this study is to determine the political communication strategy in winning the regional head candidate pair. The theory used in this study is the theory of political communication strategy and the descriptions of other supporting theories about political communication strategies. The research method used is descriptive qualitative case study. The data used in this study include primary and secondary data. Primary data is obtained from interviews with seven informants from the Hendri-ita winning post. Meanwhile, secondary data is obtained from journal literature, literature study, and documentation. Data analysis in this study followed the guidelines of the case study research design. The results of this study indicate that the political communication strategy of the regional head candidate pair is carried out by considering the characteristics of the communication components which are communicators, message content, media, communicants, and feedback. Afterwards, through the consideration of the communication. The communication strategy gave the regional head candidate pair victory in the 2020 Semarang regional head election.
\end{abstract}

Keyword: Strategy; Political Communication; Winning Regional Heads.

\begin{abstract}
Abstrak
Penelitian ini di latar belakangi pentingnya strategi komunikasi politik untuk pemenangan dalam pemilihan kepala daerah. Tujuan penelitian ini untuk mengetahui strategi komunikasi politik dalam memenangkan pasangan calon kepala daerah. Teori yang dipakai dalam penelitian ini teori Strategi komunikasi politik dan uraian-uraian teori pendukung lain nya tentang strategi komunikasi politik. Metode penelitian yang digunakan adalah deskriptif kualitatif yang bersifat studi kasus. Data yang digunakan dalam penelitian ini meliputi data primer dan sekunder. Data primer diperoleh dari wawacara dengan tujuh informan dari posko pemenangan Hendri-ita. Sementara data sekunder diperoleh dari literatur jurnal, studi kepustakaan maupun dokumentasi. Analisis data pada penelitian ini mengikuti pedoman dari design penelitian studi kasus. Hasil penelitian ini menunjukan bahwa strategi komunikasi politik pasangan calon kepala daerah dilakukan dengan mempertimbangkan karakteristik dari komponen komunikasi yakni komunikator, isi pesan, media, komunikan dan umpan balik. Kemudian melalui pertimbangan komunikasi tersebut. Strategi komunikasi memberi kemenangan pasangan calon kepala daerah dalam pemilihan kepala daerah Semarang tahun 2020.
\end{abstract}

Kata Kunci: Strategi; Komunikasi Politik; Pemenangan Kepala Daerah.

doi: https://doi.org/10.51544/jlmk.v5i1.2037

(C) 2021 Jurnal Lensa Mutiara Komunikasi. This is an open access article under the CC BY-SA license

Website: http://e-journal.sari-mutiara.ac.id/index.php/JLMI/

http://e-journal.sari-mutiara.ac.id 


\section{PENDAHULUAN}

Komunikasi politik menghadapi tantangan besar selama satu dasawarsa terakhir ini, terutama dalam mengatasi jarak yang semakin jauh antara masyarakat dan aktor politik terpilih (Solito \& Sorrentino, 2020). Kondisi tersebut membuat dibutuhkannya strategi komunikasi politik dimana tidak hanya terbatas pada kegiatan pemasaran politik, namun juga tentang pertukaran pesan yang berkelanjutan dengan masyarakat dalam pengambilan keputusan di dalam pemerintahan local (Kariryaa et al., 2020). Pada era saat ini, otonomi yang luas kemudian diberikan kepada daerah dan tidak lagi dikuasai sepenuhnya oleh pemerintah pusat termasuk dalam hal pemilihan presiden, wakil presiden sampai dengan kepala daerah seperti halnya gubernur, bupati dan wali kota (Sufianto, 2020). Hal ini diperkuat dalam UU Nomor 32 Tahun 2004 tentang Pemerintahan Daerah yang merupakan revisi dari Undang-Undang No. 22 Tahun 1992, telah mengubah tata cara pemilihan kepala daerah. Kepala daerah yang sebelumnya dipilih oleh Dewan Perwakilan Rakyat Daerah (DPRD) dirubah dan dipilih langsung oleh masyarakat. Ketentuan ini tertuang dalam pasal 56 ayat 1 Un No. 32 Tahun 2004 yang menyebutkan "kepala daerah dan wakil kepala daerah dipilih dalam satu pasangan calon yang dilaksanakan secara langsung, umum, bebas, rahasia, jujur dan adil".

Pemilihan kepala daerah (PILKADA) di Indonesia, merupakan produk era reformasi yang menimbulkan banyak berbagai fenomena baru, salah satunya adalah calon tunggal (Suyatno, 2016). Ajang kontestasi pilkada dengan calon tunggal pada dasarnya telah ada sejak pilkada tahun 2006 di Kota Jepara, Provinsi Jawa Tengah. Fenomena tersebut menjadi sebuah polemik yang terjadi pada pilkada tahun 2015 sehingga Mahkamah Konstitusi (MK) menetapkan putusan atas uji materiil Undang-Undang Nomor 8 tahun 2015 dengan putusan No. 100/PUUXIII/2015 MK yang memberi ketentuan untuk tetap menyelenggarakan pilkada tahun 2015 pada beberapa daerah yang memiliki satu pasang calon kepala daerah. Fenomena pasangan calon tunggal kemudian diatur dalam UU Nomor. 10 tahun 2016 tentang Perubahan Kedua atas Undang-Undang (UU) Nomor 1 tahun 2015 tentang Penetapan Peraturan Pemerintah Pengganti Undang-Undang Nomor 1 tahun 2014 tentang pemilihan gubernur, bupati, dan wali kota menjadi Undang-Undang (Rahmanto, 2018). Dalam hal ini Mahkamah Konstitusi memutuskan harus ada lawan tanding dari pasangan calon tunggal tersebut, yaitu kolom kosong.

Pada pilkada tahun 2020 angka atau jumlah calon tunggal sebanyak 25 kabupaten/kota, dimana salah satunya pasangan calon tunggal terdapat di wilayah Provinsi Jawa Tengah, yaitu Kota Semarang. Mardani Ali Sera selaku politisi dari Partai Keadilan Sejahtera (PKS) berpandangan bahwa keberadaan calon tunggal merupakan tanda sakitnya demokrasi (Ristyawati, 2020). Dalam Undang-Undang Pilkada No.10 Tahun 2016 pasal 54D menyebutkan bahwa pasangan calon tunggal dapat memenangkan konstestasi pilkada jika menang dan meraih lebih dari 50 persen dari total suara sah. Apabila hasil akhir kurang dari 50 persen alias kalah dari kolom kosong, bersadarkan Undang-Undang maka pelaksanaan pilkada ditunda ke pilkada berikutnya dan kepala daerah disisi pejabat yang ditunjuk oleh Kemendagri (Ishak, 2020).

Penetapan pasangan Hendi-Ita sebagai pasangan calon tunggal Wali Kota dan Wakil Wali Kota pada ajang kontestasi Pilwakot Semarang 2020 telah mendapat restu dan dukungan dari 14 (empatbelas) partai yang duduk di parlemen serta non-parlemen. Berkat dukungan tersebut, justru membuat kekhawatiran bagi pasangan calon Hendi-Ita dan tim kampanye yang dibentuknya Hendi-Ita berkaitan dengan partisipasi masyarakat dalam memberikan haknya pada kontestasi Pilwakot Semarang 2020. Hal tersebut dikarenakan Hendi-Ita dan tim kampanye merasa khawatir jika ditetapkan sebagai pasangan calon tunggal dalam Pilwakot Semarang 2020 justru membuat masyarakat kota Semarang enggan datang ke tempat pemungutan suara (TPS), 
serta adanya pandemi COVID-19 yang melanda Indonesia juga berdampak menurunkan partisipasi masyarakat.

adanya pandemi COVID-19 ini mengharuskan partai politik, para kontestan dan masyarakat untuk mematuhi protokol kesehatan COVID-19 berdasarkan anjuran dari pemerintah setempat.

Hal ini membuat setiap partai politik dan kontestan harus bekerja lebih keras lagi untuk mengumpulkan suara dalam pemilihan, karena tidak diadakannya kampanye dan sosialiasi terbuka oleh partai politik dan kontestan akan sulit meyakinkan pemilih untuk menentukan pilihan. Pasal 60 ayat (3) dalam Peraturan Komisi Pemilihan Umum dinyatakan bahwa selain bahan kampanye yang telah ditentukan dalam Peraturan KPU yang mengatur mengenai kampanye pemilihan, partai politik atau gabungan partai politik, pasangan calon dan tim kampanye dapat membuat dan mencetak bahan kampanye berupa alat pelindung diri yang terdiri atas masker, sarung tangan, pelindung wajah (face shield), cairan antiseptik berbasis alkohol (handsanitizer). Serta menyiapkan strategi komunikasi politik melalui bentuk-bentuk kampanye dengan memanfaatkan teknologi sebagai sarana komunikasi berbasis digital melalui penggunaan media baru.

Kehadiran internet telah mengubah budaya komunikasi secara signifikan (Kaul, 2020). Perkembangan teknologi dapat mendukung kemudahan manusia untuk berinteraksi dan bertukar informasi dalam berbagai aspek kehidupan, baik itu ekonomi, sosial, politik dan budaya (Söderholm et al., 2019). Penggunaan media terutama pada penggunaan media digital dan sosial lainnya membuat pengguna dapat secara aktif dalam menerima informasi dan berita yang diperolehnya (Bonnes et al., 2020). Pengguna media digital dan sosial dapat mengkonsumsi, memproduksi, dan mendistribusikan berita dan informasi serta dapat menjadi saran berinteraksi dan berdiskusi secara pribadi mengenai informasi yang diterima (Ekowati, 2019). Adanya peran media digital dalam bidang komunikasi dan politik dirasa mampu mempengaruhi opini publik menjadi solusi pengganti kampanye tatap muka yang dapat digunakan untuk mengkampanyekan beberapa program dari pasangan calon wali kota dan wakil wali kota dimasa pandemi COVID19 dengan segala keterbatasan kegiatan masyarakat yang berlaku di Kota Semarang.

Maka berdasarkan penjelasan latar belakang tersebut, penulis tertarik untuk melakukan suatu penelitian untuk mengetahui bentuk-bentuk strategi komunikasi politik tim pemenangan pasangan Hendrar Prihadi dan Hevearita Gunaryanti Rahayu dalam memenangkan konstestasi politik Pilkada pada Pemilihan Wali Kota dan Wakil Wali Kota Semarang tahun 2020.

\section{TINJAUAN LITERATUR}

\section{Komunikasi}

Dalam ilmu komunikasi, komunikasi merupakan proses penggabungan pesan-pesan sekaligus informasi agar terjadi saling pengertian (Supriyatno, 2011). Komunikasi mempunyai tujuan agar tercipta sebuah kebaikan bersama, terwujudnya kesetaraan, keadilan, keharmonisan serta kedamaian hidup (Philippe J. Maarek \& Maarek, 2014). Komunikasi berasal dari bahasa latin"Communis"atau“Common" dalam bahasa inggris yang berarti sama. Berkomunikasi berarti kita sedang berusaha untuk mencapai kesamaan makna, "Commonness", atau dengan ungkapan lain melalui komunikasi seseorang mencoba berbagi informasi, gagasan, atau sikap kita sering mempunyai makna yang berbeda terhadap lambang yang sama (Suhardjo et al., 2019). Hepp (2020) memberikan gambaran bahwa ilmu komunikasi merupakan upaya yang sistematis untuk merumuskan secara tegar asas-asas penyampaian informasi serta pembentukan pendapat dan sikap. 
Kegiatan komunikasi memiliki tiga tujuan, yaitu: mengetahui sesuatu, untuk memberikan sesuatu dan mempengaruhi serta mengarahkan agar orang lain untuk berbuat sesuatu (Azis et al., 2020). Dalam mencapai tujuan komunikasi yang efektif, paradigma Hepp (2020) mengatakan bahwa cara yang baik untuk menjelaskan komunikasi terdapat lima unsur meliputi, komunikator, pesan, media, komunikan dan efek. Maka, dalam proses menyampaikan pesan oleh komunikator kepada komunikan dapat dikatakan efektif apabila media yang digunakan dalam penyampaian pesan dapat menimbulkan efek tertentu (Hepp, 2020).

\section{Politik}

Dalam ilmu politik, politik berasal dari kata "polis" yang berarti negara atau kota, yang secara totalitas merupakan kesatuan antara negara dan masyarakat sekitarnya (Leonard, 2019). Kata polis berkembang menjadi "politicos" yang mempunyai arti kewarganegaraan (Scoones, 2016). Dari kata "politicos" menjadi "politera" yang berarti hak berkewarganegaraan (Ruppert et al., 2017).

Politik merupakan suatu disiplin ilmu pengetahuan yang berdiri sendiri karena memiliki objek, subjek, metodologi, sistem, terminologi, ciri, teori yang khas dan spesifik serta diterima secara universal diseluruh dunia dan bisa dipelajari oleh orang banyak (Le Galès, 2021). Leonard, (2019) memberikan pendapat tentang politik, dimana politik merupakan suatu kegiatan dalam suatu sistem politik yang menyangkut proses menentukan tujuan dari seluruh lapisan masyarakat (public goals) termasuk didalamnya ada tujuan dari partai politik.

\section{Komunikasi politik}

Theocharis dan Jungherr (2021) mendefinisikan suatu rumusan bahwa komunikasi politik merupakan bentuk komunikasi yang diarahkan untuk pencapaian suatu pengaruh, sehingga masalah yang dibahas mengenai semua kegiatan dalam lingkup komunikasi dapat mengikat semua warga melalui suatu sanksi yang telah ditentukan bersama oleh lembaga-lembaga politik. Street (2020) mengartikan bahwa, komunikasi politik merupakan bentuk dalam penyampaian pesan, baik yang digambarkan kedalam bentuk lambang maupun dalam bentuk kata tertulis, yang terucapkan ataupun dalam bentuk isyarat, sehingga dapat mempengaruhi kedudukan seseorang yang ada dalam suatu struktur kekuasaan tertentu. Sedangkan dalam arti luas, komunikasi politik merupakan jenis penyampaian pesan yang bermuatan informasi politik dari suatu sumber kepada para penerima pesan (Sánchez Medero, 2020).

Rodriguez Andres (2016) menjelaskan secara umum bentuk komunikasi politik yang sering digunakan oleh komunikator didalam menyusun infrastruktur politik dalam mencapai tujuannya, antara lain:

Pertama, Retorika. Merupakan bahasa yang berasal dari bahasa Yunani "rhetorica" artinya seni berbicara. Pada awalnya retorika ini digunakan dalam perdebatan yang terjadi diruang sidang pengadilan, dengan tujuan saling mempengaruhi.

Kedua, Agitasi Politik. Merupakan dari bahasa latin, agitare. Artinya bergerak atau menggerakkan. Jika diterjemahkan kedalam bahasa Inggris, berarti agitation. Agitasi dapat beroperasi untuk membangkitkan rakyat terhadap suatu gerakan politik, baik lisan maupun tulisan, dengan merangsang dan membangkitkan emosi khalayak.

Ketiga, Propaganda. Berasal dari bahasa Latin, propagare yang berarti menanamkan tunas pada tanaman. Propaganda dipergunakan sebagai bentuk kegiatan penyebaran agama Katolik dengan menumbuhkan keimanan kristiani diantara bangsa-bangsa. Hal ini banyak digunakan oleh aktor politik atau kader partai politik yang memiliki kemampuan dalam melakukan sugesti kepada khalayak serta menciptakan suasana yang dengan mudah terkena 
sugesti (sugestivitas).

Keempat, Public Relation (PR) Politik, merupakan bentuk dan upaya alternatif dalam mengimbangi propaganda yang dianggap membahayakan kehidupan sosial politik.

Kelima, Kampanye Politik, merupakan bentuk komunikasi politik yang dilakukan aktor politik atau sekelompok/organisasi dalam waktu tertentu, untuk memperoleh atau memperkuat dukungan politik dari rakyat atau pemilih. Rogers dan Storey (1987) (dalam Venus, 2004:7) menggambarkan bahwa kampanye politik merupakan serangkaian tindakan komunikasi yang terencana dengan matang, bertujuan untuk menciptakan efek tertentu pada sejumlah besar khalayak yang dilakukan secara berkelanjutan.

Keenam, Lobi Politik. Lobi sendiri sesungguhnya merupakan tempat para tamu menunggu sekaligus berbincang di sebuah hotel. Lobi politik dapat digambarkan pada event/kegiatan yang dihadiri oleh para politikus, lalu berbincang perihal politik (political lobbying) selanjutnya terjadi dialog tatap muka (komunikasi antarpersonal) secara informal namun penting. Dalam lobi tersebut biasanya ada kesepahaman dan kesepakatan bersama yang akan diperkuat melalui pembicaraan formal dalam rapat atau sidang politik yang akan menghasilkan keputusan dan sikap politik tertentu.

Ketujuh, Media Massa. McLuhan (1971) berpendapat bahwa media massa merupakan sebagai perluasan panca indera manusia (sense extension theory) dan sebagai sarana penyampaian pesan politik (the medium in the message) kepada khalayak luas untuk mendapatkan pengaruh, kekuasaan-otoritas, membentuk dan mengubah opini publik atau dukungan serta citra politik, yang tidak terjangkau pada bentuk komunikasi lainnya.

\section{Strategi Komunikasi Politik}

Kata strategi berasal dari bahasa Yunani, yakni stratogos yang memiliki arti militer dan memimpin. Awalnya, strategi diartikan sebagai generalship atau sesuatu yang dilakukan jendral dalam membuat rencana dengan tujuan menaklukan musuh serta memenangkan sebuah peperangan. Maka diawal perkembangannya, strategi sangat populer digunakan dilingkungan militer (Schäfer, 2021).

Strategi merupakan langkah prioritas yang diambil setiap organisasi melalui berbagai cara dan pilihan tentang rencana terbaik dalam mencapai misi organisasi tersebut. (Nounkeu, 2020) Pencapaian misi tersebut dapat diraih melalui tiga tahapan strategi, yaitu: perencanaan, pelaksanaan dan evaluasi strategi (Sasilo et al., 2020). Pengertian lain dari strategi yakni, strategi merupakan sebuah perencanaan (planning) dan manajemen (management) untuk mencapai suatu tujuan (Lilleker \& Koc-Michalska, 2013). Dalam mencapai tujuan tersebut, strategi tidak berfungsi sebagai peta jalan yang menunjukan arah saja, melainkan strategi harus mampu menunjukkan tentang taktik operasionalnya (Strikovic et al., 2020).

De Bruycker \& Rooduijn (2021) menjelaskan terkait lima (5) definisi strategi yang terdiri dari: strategi merupakan sebuah rencana (plan), pola (pattern), posisi (positions), permainan/taktik (play) dan sebagai perspektif (perspective).

Pertama, Strategi sama dengan rencana (Plan). Menurutnya, strategi merupakan program terencana (a directed course of action) dalam mencapai serangkaian tujuan atau goals yang telah di tentukan. Konsep ini dinamakan strategi perencanaan.

Kedua, Strategi merupakan pola (Patern). Merupakan sebuah pola perilaku masa lalu yang konsisten dan tidak berubah-ubah. Dalam pelaksanaan strategi, hal yang paling utama adalah kesadaran dari seluruh yang terlibat dengan menggunakan strategi yang telah terencana atau diniatkan. Hal yang merupakan pola berbeda dengan berniat atau bermaksud maka strategi 
sebagai pola lebih mengacu pada sesuatu yang muncul begitu saja (emergent).

Ketiga, Strategi merupakan posisi (Position). Hal ini dapat diartikan pada sebuah cara atau langkah dalam menetapkan atau menentukan sebuah merek, produk maupun posisi perusahan dalam pasar. Berdasarkan kerangka konseptual para pengguna maupun para penentu kebijakan, maka strategi utama telah ditetapkan oleh faktor-faktor eksternal.

Keempat, Strategi adalah taktik (Play). Merupakan sebuah serangan yang dibuat terencana hingga membuat untuk memperdaya atau memukau lawan (competitor).

Kelima, Strategi semacam perspektif (Prespectif). Merupakan langkah dalam melaksanakan strategi berdasarkan teori dengan mengunakan daya pikir yang wajar dari isi cara berpikir rasional ataupun ideologis.

\section{Strategi Kampanye Politik Digital.}

Kampanye, berasal dari bahasa Inggris yaitu champaign (Liebhart \& Bernhardt, 2017). Bossetta (2018) menyatakan bahwa kampanye merupakan serangkaian kegiatan komunikasi antar organisasi dengan tujuan menciptakan dampak tertentu, terhadap sebagian besar khalayak sasaran secara berkelanjutan dalam periode tertentu. Sedangkan berkaitan dengan kampanye politik bahwa kampanye politik merupakan salah satu agenda dalam kegiatan komunikasi politik pada proses pemilu, pemilukada, pilpres yang memiliki peraturan tersendiri, yang didalamnya terdapat jadwal, tata caranya, pengawasan dan sanksi-sanksi jika terjadi pelanggaran (Kreiss \& Mcgregor, 2018).

Dalam kampanye politik, komunikator politik sering disebut jurkam (juru kampanye) yang harus didaftarkan pada komisi pemilihan umum (Rahyadi \& Aras, 2020). Jurkam mempunyai tanggung jawab dalam hal ini merumuskan gagasan, tema kampanye, membuat perencanaan guna mencapai tujuan yang efektif dan efisien dalam membangun citra politik dan mempengaruhi, membentuk dan membina opini publik yang positif (Chester \& Montgomery, 2019). Selain itu, jurkam dan tim sukses juga diharuskan untuk merancang model kampanye, baik dalam model kampanye offline maupun online (Chester \& Montgomery, 2017). Bentuk saluran kampanye dengan memanfaatkan teknologi serta jenis media baru yang kerap digunakan aktor politik kedalam bentuk baru yang lebih inovatif, seperti contoh:

Pertama, Media Sosial. Media sosial merupakan media online berbasis web yang secara mudah bagi penggunanya dapat saling berpartisipasi, mulai dari berbagi informasi, menciptakan isi pesan hingga mendistribusikan pada akun media sosial tersebut (Omotayo \& Folorunso, 2020). Tidak hanya itu saja, media sosial memungkinkan orang untuk berinteraksi dalam jalinan antar komunitas. Lebih spesifik lagi, media sosial dengan mudah memberikan kemudahan kedalam bentuk pertukaran informasi yang lebih inovatif, hingga dapat bekerjasama menghasilkan sesuatu dalam bentuk tulisan visual dan audio visual yang telah terfasilitasi di media sosial Instagram, Facebook, blog hingga Twitter.

Kedua, Video mapping. Video mapping merupakan metode baru hasil sebuah karya seni pencitraan proyeksi pencahayaan dengan teknologi (Elmer \& Langlois, 2013). Video mapping dapat dihasilkan dari dua komponen, antara teknik dan pencahayaan atau proyeksi cahaya hingga menciptakan sesuatu yang baru dan kreatif (ilusi optis) yang dipantulkan pada objek tertentu. Secara visualnya, kemampuan yang dihasilakan dari video mapping ini memberikan gambar yang hidup serta dapat berubah bentuk sesuai apa telah dikonsep atau didesign menggunakan komputer kemudian disambungkan ke mesin proyektor. Hasilnya dapat dinikmati melalu pantuan cahaya pada sebuah bidang datar. 
Ketiga, Teknologi Hologram box. Teknologi hologram box memungkinkan adanya interaksi sesama pengguna layaknya dalam dunia hiburan dan film (Kazempourradi et al., 2019). Pengoperasiannya dengan mudah menggunakan jaringan konektivitas bluetooth yang tersemat di smartphone. Selain untuk hiburan yang inovatif, teknologi hologram box juga sering dimanfaatkan perusahaan untuk kepentingan bisnisnya maupun kampanye. Selain itu, hologram box juga memiliki keunggulan dalam membentuk branding serta dapat menarik perhatian audiens sebagai ruang penyampaian informasi.

Keempat, Virtual (Champaign). Virtual merupakan pengembangan metode baru dalam komunikasi, yang dilakukan secara maya menggunakan perangkat internet, gawai serta aplikasi (Elerud-Tryde \& Hooge, 2014). Pada kehidupan nyata, virtual difungsikan dalam berbagai bidang, baik itu pendidikan, bisnis, sosial, kemasyarakatan hingga politik. Virtual merupakan bentuk komunikasi langsung tanpa bertemu secara nyata menggunakan seperangkat media yang perlu disiapkan seperti halnya gawai, ponsel pintar, komputer, laptop, smart TV hingga notebook. Selain gawai dan seperangkat diatas, virtual champaign sangat membutuhkan jaringan internet yang kuat serta aplikasi yang berfungsi sebagai ruang bertemu hingga menghasilkan komunikasi mirip seperti kenyataan sebenarnya.

\section{METODE PENELITIAN}

Penelitian ini merupakan penelitian kualitatif bersifat deskriptif yang bertujuan untuk menjelaskan, menggambarkan dan memahami fenomena sosial dari sudut pandang atau perspektif subyek/partisipan. Subyek dalam penelitian adalah orang-orang yang terlibat dalam sebuah realitas dan memberikan data/informasi kepada peneliti. Pendekatan yang dilakukan pada penelitian ini menggunakan pendekatan kualitatif dengan design studi kasus (case study). Studi kasus merupakan penelitian yang meneliti tentang fenomena kontemporer secara utuh dan menyeluruh pada kondisi yang sebenarnya, dengan kata lain bahwa kasus yang akan diteliti tersebut sedang atau telah selesai terjadi, tetapi masih memiliki dampak.

Sumber data yang digunakan dalam penelitian yakni: data primer dan data sekunder. Data primer didapat peneliti melalui catatan dilapangan, rekaman kata-kata yang diperoleh dari wawancara mendalam (indepth interview) kepada tujuh informan dari posko pemenangan Hendri-ita. Untuk mendapatkan data sekunder, maka peneliti akan menggunakan literatur jurnal, studi kepustakaan maupun dokumentasi. Untuk memperoleh data primer, peneliti menggunakan panduan wawancara guna melakukan teknik wawancara mendalam (indepth interview). Sedangkan untuk melengkapi data sekunder, maka peneliti akan mengumpulkan data berupa dokumen dan foto dokumentasi.

Pada penelitian ini, peneliti menggunakan model analisis data sesuai dengan design penelitian studi kasus. Dalam merumuskan strategi tersebut terdapat 3 (tiga) bentuk analisis yang dapat dipergunakan, yaitu:

1. Penjodohan pola, keknik analisis ini dapat menggunakan logika penjodohan pola. Logika penjodohan pola dapat dilakukan guna membandingkan pola berdasarkan data empirik dengan pola yang diprediksi.

2. Pembuatan eksplanasi, teknik ini dapat digunakan untuk menganalisis data dari kasus yang diteliti dengan cara membuat suatu eksplanasi (menjelaskan tentang proses terjadinya kasus yang bersangkutan).

3. Analisis deret waktu, teknik ini mirip dengan investigasi pengaturan waktu yang diarahkan pada pemeriksaan atau eksperimen dan kuasi-eksperimental. Namun, mengenai deret waktu 
dalam studi kasus mencoba untuk menyelidiki suatu pola informasi dari waktu ke waktu, tentatif atau reflektif, mengenai pengelompokan atau waktu.

4. Verifikasi, baik dari segi makna dan kebenaran. Sajian data yang telah disusun secara sistematis, yang selanjutnya peneliti dapat menarik sebuah kesimpulan. Jika dirasa memerlukan data baru, maka peneliti wajib melakukan mengumpulkan data kembali hingga analisis data yang dihasilkan dirasa cukup matang

\section{HASIL DAN PEMBAHASAN}

Strategi pemenangan Pemilukada sangat dipengaruhi bagaimana pasangan calon dapat mempengaruhi pemilih untuk tujuan membentuk perilaku pemilih (Tilome et al., 2020). Pada dasarnya kandidat adalah produsen yang mampu memasarkan diri sebagai proses pemasaran politik (Cibro, 2018). Pasangan Hendrar Prihadi dan Hevearita Gunaryanti Rahayu pada pentas Pemilukada 2020 di Semarang Jawa Tengah lebih mengandalkan kekuatan komunikasi politik yang dijalin dengan masyarakat.

Berdasarkan hasil wawancara maka dapat dikemukakan bahwa strategi komunikasi politik tim pemenangan Hendrar Prihadi dan Hevearita Gunaryanti Rahayu dilakukan dengan pendekataan yang terdiri atas pemilihan komunikator. Berdasarkan hasil wawancara didapatkan gambaran bahwa strategi komunikasi dilakukan oleh ketua tim pemenangan dan juga calon pasangan. Strategi komunikasi tersebut menunjukan bahwa penyampaian pesan -pesan politik untuk mempengaruhi msyarakat agar mendukung kandidat tidak hanya dilakukan ketua tim pemenangan tetapi juga dilakukan oleh pasangan calon. Pesan-pesan yang disampaikan kepada masyarakat tidak terlepas terhadap situasi yang ada di daerah, tim pemenangan bekerja extra lebih keras untuk menyambungkan pesan-pesan yang disampaikan pasangan calon kepada masyarakat melalui tim pemenangan.masyarakat yang pro. Sementara yang kontra akan di tampung aspirasinya oleh calon pasangan melalui tim pemenangan.

Dalam pengaplikasian strateginya, pasangan dan tim pemenangan mengandalkan agenda rutin pertemuan warga dengan melakukan follow up untuk melihat kekurangan yang terjadi saat pertemuan dan merumuskan strategi baru dalam bentuk lain. Bentuk sosialisasi dengan melakukan pertemuan dirumah warga didukung oleh kemampuan kandidat dan tim dalam melakukan strategi push dan pass untuk membentuk simpati melalui aktivitas yang sekaligus melibatkan partisipasi masyarakat. Mengingat dalam menciptakan kerjasama dan kolaborasi antara kandidat dengan masyarakat dibutuhkan proses komunikasi dua arah. Adanya komunikasi dua arah antara kandidat atau tim pemenangan dapat menghasilkan reaksi konstituen dan masyarakat pemilih terhadap apa yang telah dilakukan berdasarkan perencanaan yang telah dibuat.

Liddle (2021) mengungkapkan, hubungan antara partai politik dengan masyarakat adalah hubungan interasi. Kedua pihak terlibat dalam membangun pemahaman bersama. Hal ini perlu dilakukan karena partai politik dan masyarakat memiliki kerangka berfikir yang berbeda. Komunikasi dua arah membutuhkan proses sense-giving dan sensemaking Mangan et al. (1981). Sense-giving adalah suatu proses komunikasi ketika partai politik mencoba mengkomunikasikan ide dan gagasan partai, program kerja dan platform, serta ideologi partai ke masyarakat dan konstituen mereka. Tujuan utama dari proses ini adalah agar hal-hal yang diperkirakan dan direncanakan partai politik bersangkutan dapat diterima dan dimengerti oleh para konstituen dan masyarakat luas. Sedangkan sense-making, di mana masyarakat dan konstituen akan memberikan tanda-tanda reaksi mereka atas apa yang dikomunikasikan oleh partai politik. Atau, proses juga dapat terjadi sebelum partai politik mengkomunikasikan program kerja mereka. 
Senada dengan pendapat diatas, Saud et al. (2020) berasumsi tentang konsep komunikasi interpersonal bahwa ketika orang berkomunikasi, mereka membuat prediksi tentang efek dari perilaku komunikasi mereka, mereka memilih bermacam strategi komunikatif tentang bagiamana komunikan akan merespon.

Pemanfaatan media dalam bentuk apapun merupakan saluran komunikasi kandidat kepada pemilih dapat dianggap efektif dan efisien pada masa kampanye (Tomin et al., 2020). Berkampanye melalui media merupakan hal yang biasa dalam dunia politik modern. Penggunaan media dalam komunikasi politik saat kampanye sangat penting (Harknett \& Smeets, 2020). Kecermatan memilih media kampanye harus disesuaikan dengan kondisi dan situasi khalayak. Penggunaan media massa dalam kampanye merupakan salah satu saluran komunikasi kandidat kepada pemilih dan cakupan daerah yang lebih luas (Vasko \& Trilling, 2019). Dalam kampanye modern pengunaan media massa kerap dilakukan sebagai strategi pembentukan citra konstestan.

Media yang digunakan oleh Hendrar Prihadi dan Hevearita Gunaryanti Rahayu yaitu media cetak dan media elektronik. Cukup ampuh menyebarkan visi dan misi pasangan tersebut dan menerima aspirasi masyarakat. Efek yang dirasakan Begitu antusiasnya masyarakat menantikan pemimpin yang bisa merubah daerah menjadi lebih baik lagi, masukan/tanggapan masyarakat kepada mereka akan mereka evaluasi sebaik mungkin guna menjadikan pelajaran kepada mereka. Sebagai tim pemenangan tugas utama yaitu selain menyampaikan visi dan misi kandidat juga menerima aspirasi atau masukan kepada mereka.

Perloff (2015) berpendapat bahwa media massa pada dasarnya hanya mampu berada pada tataran pembentukan citra (image), sementara yang berperan untuk mengajak orang mengubah pilihan adalah komunikasi antarpribadi. Media hanya memberi pengaruh pada hal-hal yang sifatnya singkat dan tidak lama (sort term). Oleh karena itu, Sander dan Pace mengusulkan agar pemilu menekankan pada image world view daripada isu-isu. Sebab para pemilih pada umumnya cenderung untuk mengikuti hanya pada awal dan akhir kampanye (Saijo, 2020).

\section{KESIMPULAN}

Pendekatan komunikasi politik tidak hanya dilakukan oleh kandidat saja, melainka juga oleh tim pemenangan. Pesan yang disampaikan oleh tim pemenangan dan pasangan Hendrar Prihadi dan Hevearita Gunaryanti Rahayu kepada masyarakat tentu nya mudah dipahami, mudah di mengerti, dan tidak berbelit-belit. Hal ini menjadi penting dikarenakan pesan yang disampaikan harus bisa diterima oleh masyarakat. Pada media yang dipakai oleh tim pemenangan dan pasangan Hendrar Prihadi dan Hevearita Gunaryanti Rahayu yaitu radio dan media cetak sangat ampuh digunakan untuk meyakinkan masyarakat mengenai visi dan misi pasangan tersebut. Tim Pemenangan pasangan Hendrar Prihadi dan Hevearita Gunaryanti Rahayu juga berperan dalam menampung aspirasi masyarakat ketika ada sebagian masyarakat tidak pro kepada kandidat calon.

\section{DAFTAR PUSTAKA}

Azis, H., Pawito, P., \& Satyawan, A. (2020). EXAMINING COMMUNICATION MEDIATION MODEL ON YOUTH ONLINE POLITICAL ENGAGEMENT. Profetik: Jurnal Komunikasi. https://doi.org/10.14421/pjk.v13i2.1841

Bonnes, C., Leiser, C., Schmidt-Hertha, B., Rott, K. J., \& Hochholdinger, S. (2020). The relationship between trainers' media-didactical competence and media-didactical selfefficacy, attitudes and use of digital media in training. International Journal of 
Training and Development. https://doi.org/10.1111/ijtd.12171

Bossetta, M. (2018). The Digital Architectures of Social Media: Comparing Political Campaigning on Facebook, Twitter, Instagram, and Snapchat in the 2016 U.S. Election. Journalism and Mass Communication Quarterly. https://doi.org/10.1177/1077699018763307

Chester, J., \& Montgomery, K. C. (2017). The role of digital marketing in political campaigns. Internet Policy Review. https://doi.org/10.14763/2017.4.773

Chester, J., \& Montgomery, K. C. (2019). The digital commercialisation of us politics 2020 and beyond. Internet Policy Review. https://doi.org/10.14763/2019.4.1443

Cibro, R. (2018). Strategi Komunikasi Politik Dalam Pemilihan Kepala Daerah Di Aceh Singkil ( Studi Kasus Tentang Strategi Komunikasi Politik Pasangan Dulmusrid Sazali Pada Pemilihan Bupati Aceh Singkil Tahun 2017 ). 1-117.

De Bruycker, I., \& Rooduijn, M. (2021). The People's Champions? Populist Communication as a Contextually Dependent Political Strategy. Journalism and Mass Communication Quarterly. https://doi.org/10.1177/1077699021998648

Ekowati, E. Y. (2019). The Effectiveness of Social Media as a Tool for Regional Election Campaign in Indonesia. https://doi.org/10.5220/0008815700050009

Elerud-Tryde, A., \& Hooge, S. (2014). Beyond the generation of ideas: Virtual idea campaigns to spur creativity and innovation. Creativity and Innovation Management. https://doi.org/10.1111/caim.12066

Elmer, G., \& Langlois, G. (2013). Networked campaigns: Traffic tags and cross platform analysis on the web. Information Polity. https://doi.org/10.3233/IP-2011-0244

Harknett, R. J., \& Smeets, M. (2020). Cyber campaigns and strategic outcomes. Journal of Strategic Studies. https://doi.org/10.1080/01402390.2020.1732354

Hepp, A. (2020). Artificial companions, social bots and work bots: communicative robots as research objects of media and communication studies. Media, Culture and Society. https://doi.org/10.1177/0163443720916412

Ishak, N. (2020). Problematika Pemilihan Kepala Daerah Calon Tunggal Dalam Demokrasi Indonesia. Pena Justisia: Media Komunikasi Dan Kajian Hukum. https://doi.org/10.31941/pj.v19i2.1144

Kariryaa, A., Rundé, S., Heuer, H., Jungherr, A., \& Schöning, J. (2020). The Role of Flag Emoji in Online Political Communication. Social Science Computer Review. https://doi.org/10.1177/0894439320909085

Kaul, V. (2020). The Digital Communications Revolution. Online Journal of Communication and Media Technologies. https://doi.org/10.29333/ojcmt/2392

Kazempourradi, S., Ulusoy, E., \& Urey, H. (2019). Full-color computational holographic near-eye display. Journal of Information Display. https://doi.org/10.1080/15980316.2019.1606859

Kreiss, D., \& Mcgregor, S. C. (2018). Technology Firms Shape Political Communication: The Work of Microsoft, Facebook, Twitter, and Google With Campaigns During the 
2016 U.S. Presidential Cycle. Political Communication. https://doi.org/10.1080/10584609.2017.1364814

Le Galès, P. (2021). The Rise of Local Politics: A Global Review. In Annual Review of Political Science. https://doi.org/10.1146/annurev-polisci-041719-102158

Leonard, J. S. (2019). Politics. In Mark Twain in Context. https://doi.org/10.1017/9781108617208.017

Liddle, R. W. (2021). 6. Participation and the Political Parties. In Political Power and Communications in Indonesia. https://doi.org/10.1525/9780520311039-009

Liebhart, K., \& Bernhardt, P. (2017). Political storytelling on instagram: Key aspects of Alexander van der Bellen's successful 2016 presidential election campaign. Media and Communication. https://doi.org/10.17645/mac.v5i4.1062

Lilleker, D. G., \& Koc-Michalska, K. (2013). Online Political Communication Strategies: MEPs, E-Representation, and Self-Representation. Journal of Information Technology and Politics. https://doi.org/10.1080/19331681.2012.758071

Mangan, J., Jackson, K. D., \& Pye, L. W. (1981). Political Power and Communications in Indonesia. Journal of the American Oriental Society. https://doi.org/10.2307/601235

Nounkeu, C. T. (2020). Political communication strategies of sub-saharan africa nationalist movements in the era of (De)colonization: The case of the upc in cameroon (194856). Journal of African Media Studies. https://doi.org/10.1386/jams_00015_1

Omotayo, F. O., \& Folorunso, M. B. (2020). Use of social media for political participation by youths in Oyo State, Nigeria. EJournal of EDemocracy and Open Government. https://doi.org/10.29379/jedem.v12i1.585

Perloff, R. M. (2015). Mass Communication Research at the Crossroads: Definitional Issues and Theoretical Directions for Mass and Political Communication Scholarship in an Age of Online Media. Mass Communication and Society. https://doi.org/10.1080/15205436.2014.946997

Philippe J. Maarek, P., \& Maarek, P. (2014). Politics 2.0: New Forms of Digital Political Marketing and Political Communication. Trípodos.

Rahmanto, T. Y. (2018). Calon Tunggal dalam Perspektif Hak Memilih dan Dipilih di Provinsi Banten. Jurnal HAM. https://doi.org/10.30641/ham.2018.9.103-120

Rahyadi, I., \& Aras, M. (2020). Donald digital marketing: An exploratory study of digital political marketing in trump presidential campaign. Pertanika Journal of Social Sciences and Humanities.

Ristyawati, A. (2020). EFEKTIVITAS PELAKSANAAN PILKADA SERENTAK 2020 PADA MASA PANDEMI DARURAT COVID-19 DI INDONESIA. CREPIDO. https://doi.org/10.14710/crepido.2.2.85-96

Rodriguez Andres, R. (2016). The rise of outsider candidates as a result of the new forms of Political Communication and public disaffection. COMUNICACION Y HOMBRE.

Ruppert, E., Isin, E., \& Bigo, D. (2017). Data politics. In Big Data and Society. https://doi.org/10.1177/2053951717717749 
Saijo, H. (2020). The effects of electoral anticipation on portfolio allocation. Party Politics. https://doi.org/10.1177/1354068820914547

Sánchez Medero, R. (2020). Democratization in Political Communication. Political Studies Review. https://doi.org/10.1177/1478929920924930

Sasilo, H., Sari, S., \& Indria, I. (2020). THE POLITICAL COMMUNICATION STRATEGY OF PARTAI GOLONGAN KARYA IN REGIONAL HEAD ELECTION YEAR 2018. SENGKUNI Journal (Social Science and Humanities Studies). https://doi.org/10.37638/sengkuni.1.1.87-97

Saud, M., Ida, R., \& Mashud, M. (2020). Democratic practices and youth in political participation: a doctoral study. International Journal of Adolescence and Youth. https://doi.org/10.1080/02673843.2020.1746676

Schäfer, A. (2021). Digital heuristics: How parties strategize political communication in hybrid media environments. New Media and Society. https://doi.org/10.1177/14614448211012101

Scoones, I. (2016). The Politics of Sustainability and Development. In Annual Review of Environment and Resources. https://doi.org/10.1146/annurev-environ-110615-090039

Söderholm, P., Hellsmark, H., Frishammar, J., Hansson, J., Mossberg, J., \& Sandström, A. (2019). Technological development for sustainability: The role of network management in the innovation policy mix. Technological Forecasting and Social Change. https://doi.org/10.1016/j.techfore.2018.10.010

Solito, L., \& Sorrentino, C. (2020). Political communication and social change. Political communication and challenges in the digital age. Icono14. https://doi.org/10.7195/RI14.V16I1.1161

Street, J. (2020). Popular culture and political communication. Comunicazione Politica. https://doi.org/10.3270/96428

Strikovic, E., van der Meer, T. G. L. A., van der Goot, E., Bos, L., \& Vliegenthart, R. (2020). On Behalf of the People: The Use of Public Opinion and the Perception of "the People" in Political Communication Strategies of Dutch MPs. International Journal of Press/Politics. https://doi.org/10.1177/1940161219864297

Sufianto, D. (2020). PASANG SURUT OTONOMI DAERAH DI INDONESIA. Jurnal Academia Praja, 3(2), 271-288.

Suhardjo, I., Hidayat, D. R., Sinaga, O., \& Heryanto, G. G. (2019). The failure of communication between elite in political organization. Opcion.

Supriyatno, Y. (2011). Peran Komunikasi Politik Pemerintah Dalam Mencegah Disintegrasi Bangsa. Jurnal Kybernan.

Suyatno, S. (2016). Pemilihan Kepala Daerah (Pilkada) dan Tantangan Demokrasi Lokal di Indonesia. Politik Indonesia: Indonesian Political Science Review. https://doi.org/10.15294/jpi.v1i2.6586

Theocharis, Y., \& Jungherr, A. (2021). Computational Social Science and the Study of Political Communication. Political Communication. https://doi.org/10.1080/10584609.2020.1833121 
Tilome, A. A., Agustang, A., Jasruddin, Muhammad Syukur, \& Asrifan, A. (2020). Social Exchange of Political Elites in the Regional Leader Election of Gorontalo Province, Indonesia. Solid State ....

Tomin, V. V., Erofeeva, N. E., Borzova, T. V., Lisitzina, T. B., Rubanik, V. E., Aliyev, H. K., \& Shuaipova, P. G. (2020). Internet media as component of information and communication environment in electoral process: Features and tools. Online Journal of Communication and Media Technologies. https://doi.org/10.29333/ojcmt/7932

UU Nomor 32 Tahun 2004. (2004). Undang-Undang No 32 Tahun 2004 Tentang Pemerintah Daerah. Dpr.

Vasko, V., \& Trilling, D. (2019). A permanent campaign? Tweeting differences among members of Congress between campaign and routine periods. Journal of Information Technology and Politics. https://doi.org/10.1080/19331681.2019.1657046 